\title{
Implications of Similarities in Instructional Design, Learner Interface Design and User Interface Design in Designing a User-Friendly Online Module
}

Titilola T. Obilade MBBS, Ph.D

\begin{abstract}
The development of a user-friendly online module depends on the inputs, the processes and the outcomes from the user interface design, the learner interface design and the instructional design. The online module includes the user interface design, the learner interface and the instructional design. This chapter would examine the theories behind these three designs. What guidelines can be garnered from the theories of these three designs? How can these guidelines be used to develop a user-friendly online module? In addition, it would examine their similarities and how they can be used to develop a user-friendly online module. Further, the chapter recommended an alignment of the garnered guidelines from the three designs to explore the plausible reasons for the high attrition rate in Massive Open Online Courses (MOOC).
\end{abstract}

Keywords: Instructional Design, User Interface Design, Learner Interface Design, UserFriendly, Online Module, Processes, Inputs, Outcomes, Affordance, Minimalism, Massive Open Online Courses (MOOC).

\section{Introduction}

Many online modules exist and it is not all these websites that are user-friendly. Online modules are platforms that allow communication between the learner and the module. Usually, 
when the learner is at the computer, the designer is not going to be present. Whether the use of a website is for learning or for purchasing goods; the website needs to be user-friendly. This chapter would examine the theories in user interface design, learner interface design and instructional design. Further, it would garner guidelines from their theories. In addition, it would examine how the similarities in these three designs can be used in developing a userfriendly online module.

\section{OUTLINES FOR CHAPTER}

- User Interface

- Models of User Interface

- Some Theories of User Interface Design

- User-Friendly Guidelines from Theories of User Interface Design

- Learner Interface

- Some Theories of Learner Interface Design

- User-Friendly Guidelines from Theories of Learner Interface Design

- Instructional Design

- Some Theories of Instructional Design

- User-Friendly Guidelines from Theories of Instructional Design

- Similarities in User Interface Design, Learner Interface Design and Instructional Design

- Analogy of User Interface, Learner Interface and Instructional Design to a Car

- The Massive Online Open Courses (MOOC) Experience

- Conclusion 


\section{USER INTERFACE}

User interface design began with the design of software systems like Microsoft Disk Operating System (MS DOS), MS Windows, Windows 95, Macintosh Operating System (Mac OS and later with the development of application software like word processors, spread sheets and graphic designs (Jones \& Farquahar, 1997). There are many definitions of user interface.

"User interface is the communication medium between the user and the technology or machine" (Vrasidas, 2011, p.228). It is through the user interface that humans can talk to the computer (Galitz, 2002, Chap. 2). It is the human end of the computer (Beynon-Davies, 1993, Chap. 19). A user interface is the software and hardware of the computer that allows the user to interact with the information from the computer (Mandel, 1997, Chap. 2).

Human-computer interface and human-human interface are synonyms for the user interface (Marcus, 2002). A user interface has input and output devices. These input devices include the mouse, the finger (for touch screen), keyboard and the voice for voice recognition (Galitz, 2002, Chap.2). The screen display is an output device. A user interface is the channel of communication that occurs between the user and the computer.

Computer based instruction was initially limited to text on the computer screen that was controlled by the keystroke from the keyboard. After the introduction of the graphical user interface, instructional delivery through the computer became revamped (Jones, 1995). User interfaces should be unobtrusive in their function by allowing the user to work seamlessly with the technology (Galitz, 2002, Chap.2; Vrasidas, 2011). The user interface is made up of windows, controls, menus, buttons, metaphors, online help and documentation.

The user interface is not the Hyper Text Markup Language (HTML) code (Vrasidas, 2011). It also includes non-traditional components like trackers, $3 \mathrm{D}$ pointing devices and 
whole hand held devices (Bowman, Kruijff, LaViola \& Poupyrev, 2001). User interfaces with assistive technologies have additional icons that would indicate the type of assistive technology on the user interface (see Figure 1). The mouse pointer enhancements are an assistive technology device for the user interface.

Figure 1 The four red lines on the computer screen enclose the cursor so that users with visual challenges can quickly locate the cursor. (The red lines would appear as grey in a black and white image).

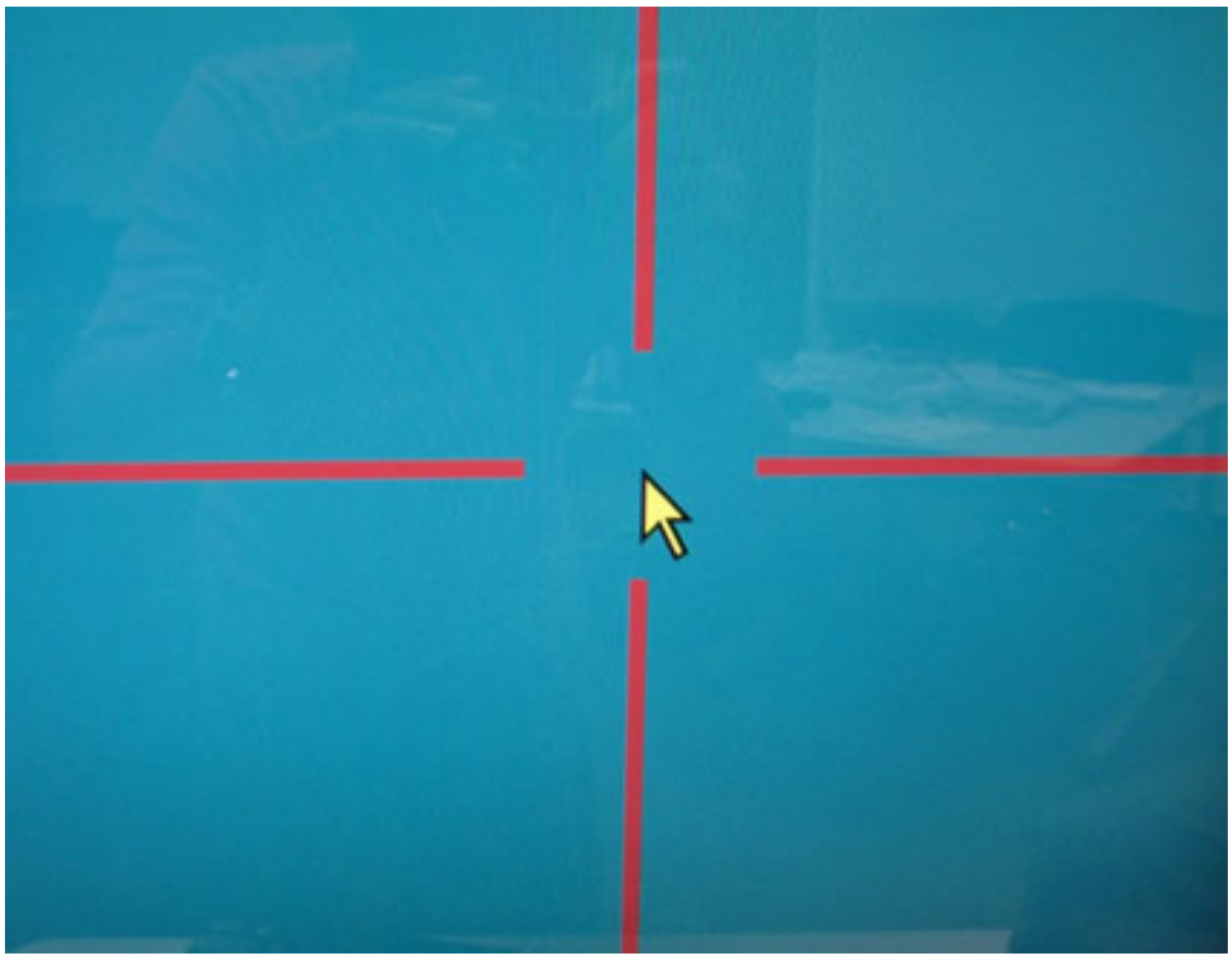

The user interface includes the software, hardware, tutorials and the manuals that come with the software and hardware (Mandel, 1997, Chap. 2). There are two main types of user interfaces; the Graphical User Interface (GUI) and the Web User Interface (see Figures $2 \& 3$ ). 
Figure 2 Screen Shot of Graphical User Interface 


\section{BOOKS - JOURNALS - E-RESOURCES - VIDEOS ONDEMAND TOPIC COLLECTIONS RESOURCES - MEDIA -}

The GUI is the "graphical representation of, and interaction with, programs, data, and objects on the computer screen" (Mandel, 1977 p.160). They usually have icons, menus and pointers. The web interface is the design of the information being presented (Galitz, 2002, Chap.2). User interface designs are used as game-based learning by integrating software applications in the learner interface (Liang, Lee \& Chou, 2010).

At the onset, the purpose of creating the web interface design was to give information. The HTML used was directed at technical people and not at the general population. Therefore, the general user has problems with the web interface today (Galitz, 2002, Chap. 2). This can be an explanation to why some web sites are not user friendly.

The World Wide Web (WWW) is an open system because beyond the page that the designer has designed for the user, the user can link to other sites not created by the designer (Jones \& Farquhar, 1997). Ritchie and Hoffman (1997) pointed out that a World Wide Web page with links to other sites is not an instructional page but it becomes an instructional web based lesson when it incorporates the principles of instructional design. Educational software is a closed system because the information provided in the software is finite. It is the designer that has the control in closed systems (Jones \& Farquhar, 1977).

\section{Models of User Interface}

There are different models of user interface. The models have functional variations. This chapter would discuss four models of user interface. 


\section{Goals, Operators, Methods and Selection Rules Model (GOMS)}

The goals, operators, methods and selection rules model (GOMS) and the keystrokelevel model were proposed by Card, Moran and Newell in 1980 (John, 2003; John \& Kieras, 1995; Shneiderman, 1998). The GOMS was developed using text editing applications but it can be applied to other task domains (John \& Kieras, 1995).

The general goal can be to write a paper and one of the several sub goals would be to edit the manuscript. The goal is what the user wants to do. The operators are the motor and the perceptual actions that take place to achieve the goal. They are controlled by the software that the user is using. The operator could be a command like delete but on a graphical user interface, it could be any of the menu selections on the computer. It could also be a gazedbased user interface (Stellmach \& Dachselt, 2012). The operator could also be a gestural interface (Lü, \& Li, 2011; Rautaray, Kumar \& Agrawal, 2012). Figure 4 shows different hand motions in front of a gestural interface.

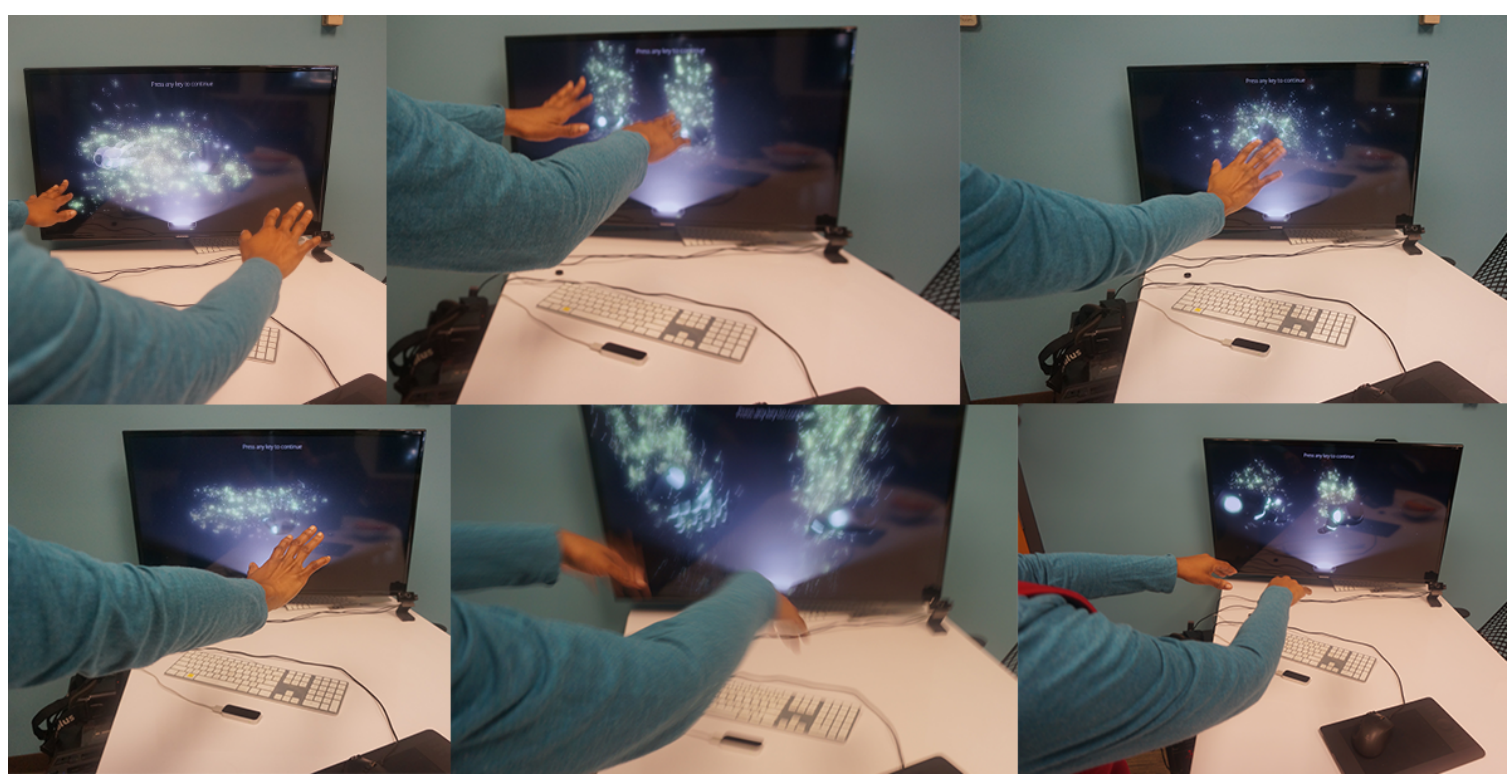

Figure 4 Gestural User Interface 
The methods are the processes used in navigating the operators and sub goals to achieve the overall goal. The selection is the different combinations of selections and operators through which the overall goals can be achieved. As an example, in writing a paper using a word processor, the user would need to use different applications like editing, pasting and deleting functions.

Hennicker and Koch (2001) proposed a user interface model that would use a conceptual, navigation and presentation design. Mandel (1997) described the user interface model as the user's model, the programmer's model and the designer's model. He further makes an analogy of a house being built; the architect designs the house like the designer, the builder builds or develops the house from the architect's design like the programmer and the user is the person or people that would be living in the house like the end user.

\section{The User's Model}

The user's model would reflect on the user. A user's model for a child may show playful icons with cartoon characters but an adult user's model would not show cartoon icons.

Regardless of the user, certain information must be extracted from the users. The designer must analyze the user. Are they novice or expert users (Shneiderman, 1998)? The designer must survey and interview potential users (Mandel, 1997). S/he should visit the work sites of the prospective users and get feedback from the users. The designers can videotape users at work (Galitz, 2002). Further, psychological characteristics of the user must be added.

These characteristics include the attitude, motivation, patience, expectations, stress level and cognitive style of the users (Galitz, 2002). In addition, the physical characteristics of the user would determine the design. These physical characteristics include the age, gender, left or 
right-handedness and disabilities of hearing, vision or a motor handicap. Hennicker and Koch (2001) proposed visual modeling and storyboarding by user interface designers.

The designers should also do a usability testing (Mandel, 1997). The term usability was first used by Bennett in 1979 and the definition rests on the effective use of the computer by humans (Galitz, 2002). Nielsen (1993) defined usability as a property of a user interface with attributes of learnability, efficiency, memorability, errors and satisfaction. He argues against such terms as user-friendly or user-centered design because a computer is made to serve the human and different users have different needs on the computer.

\section{The Programmer's Model}

Going back to the analogy of a house that was discussed under the section of GOMS, the programmer is like the house builder (Shneiderman, 1998). S/he writes the codes or the program. Johnson and Henderson (2002) suggest that before programmers begin to draw dialog boxes, they should start with a conceptual model of the design.

4. The Designer's Model. The designer is the intermediary between the programmer and the user. It is the designer that sees the user. The programmer does not meet the user (Galitz, 2002). It is the designer that describes the objects that the user works with. In addition, the designer describes how these objects are presented to the user and the interaction of the user with them (Mandel, 1997, Chap.3).

\section{Some Theories of User Interface Design}

There are several theories that are used in user interface. Some of these are Fitt's law, cognitive information processing, perception, vision research, minimalism and color theory. Shneiderman (1998, Chap. 2) asserted that there were thousands of theories existing on user interfaces. These theories can be divided into two categories (MacKenzie, 2003; Shneiderman, 
1998, Chap. 9). They can be explanatory or predictive. The explanatory theories explain concepts of designs and observable behaviors. The predictive theories relate to the execution time or error rates of tasks performed.

Fitts' Law (MacKenzie, 2003; Shneiderman, 1998, Chap. 9) is used in the design of pointing devices. Fitts' Law predicts the time it would take for the cursor to move a certain distance from the moment the pointing device is activated. It is dependent on the distance the hand has to move from the pointing object to the target object. The predictions from Fitts' Law are dependent on whether the movement is vertical or horizontal. Further, the predictions are dependent on the arm position, the device grasp and the shape of the target (Shneiderman \& Plaisant, 2010, Chap.8).

The cognitive information processing model of acquiring knowledge, retrieving information, organization and prior experience are used in designing software (MacKenzie, 2003; Mandel, 1997, Chap. 4). It explains how information is stored and retrieved. In addition to using the cognitive information processing system, design principles are based on human perception (Ware, 2003). It is through perception theory that designers can determine how many pixels can be conveniently displayed on a phone screen (Ware, 2003).

The vision research theory is used in the design of 3-dimensional user interfaces (Ware, 2003). Ware (2003) introduced the term, information psychophysics which is how humans see information patterns when the patterns are expressed through light, color and simple patterns. Color theory suggests an appropriate choice of color in the design. It is through the knowledge of color theory that Liquid Crystal Display (LCD) monitors and Cathode Ray Tubes (CTR) produce mixtures of three colors (Ware, 2003). 
However, color theory is separate from the culture that some groups attach to color. In some parts of Asia, the red color symbolizes good fortune while in Europe, it symbolizes danger (Ware, 2003). Ware (2003) argued that affordance theory could not be strictly used in the design of user interfaces because by the Gibsonian definition, affordances referred to the physical properties of the object.

However, by more recent definitions of affordance, it does not have to be a physical characteristic that can be touched (Obilade, 2015). There are different types of affordance like technological affordance, educational affordance and perceived affordance (Obilade, 2015). These newer definitions of affordance give room for the user to intuitively know how to use the product without engaging any frustrations from his/her inability to make the product perform what it is intended to do (Obilade, 2015). A perceived affordance gives clues on how to use the product (see Figures 5 \& 6). 
Figure 5 The push sign on the glass door is a perceived affordance. It gives a clue on how to open the door.

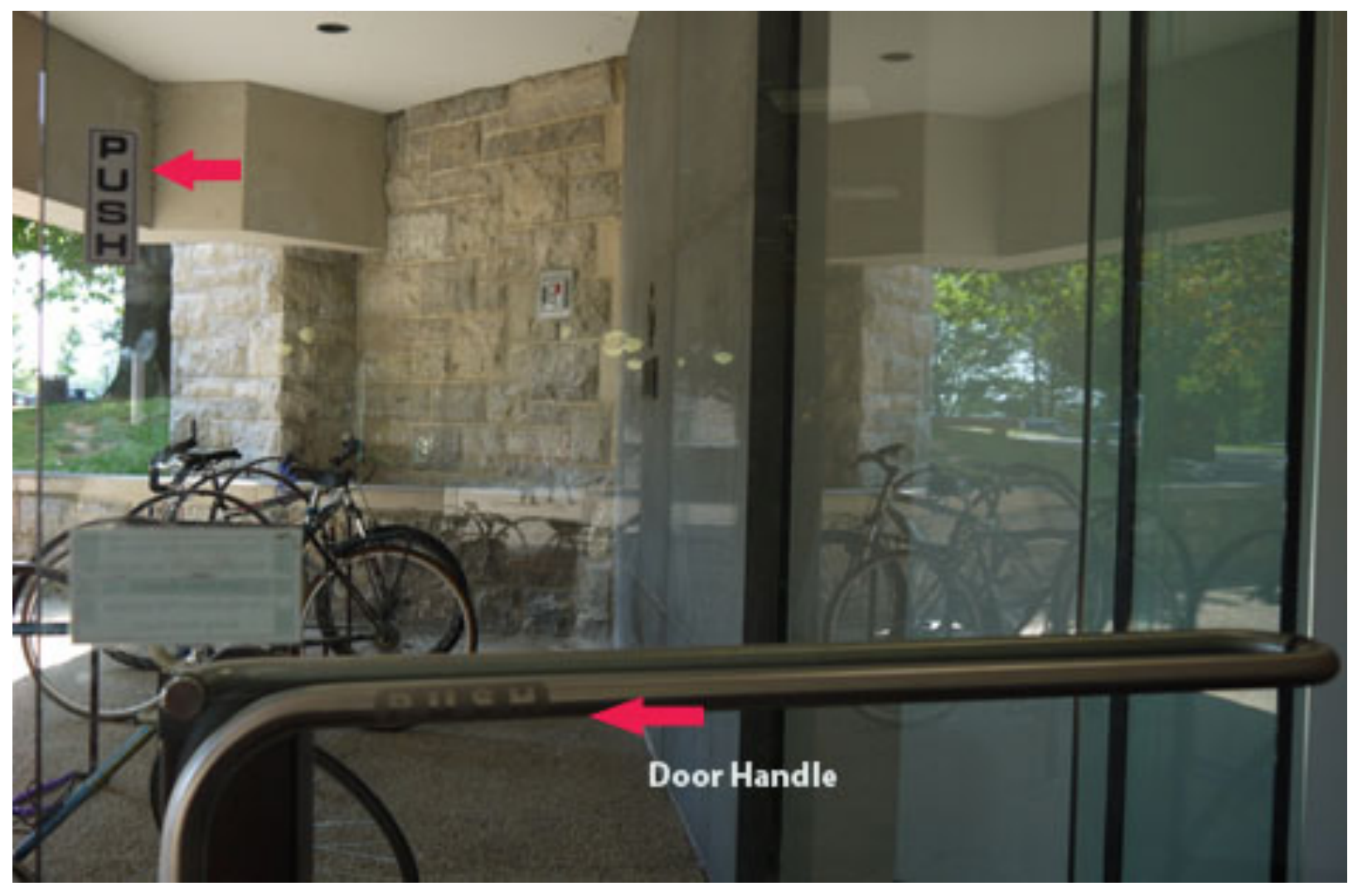


Figure 6 The pull sign on the glass door is a perceived affordance. It gives a clue on how to open the door.

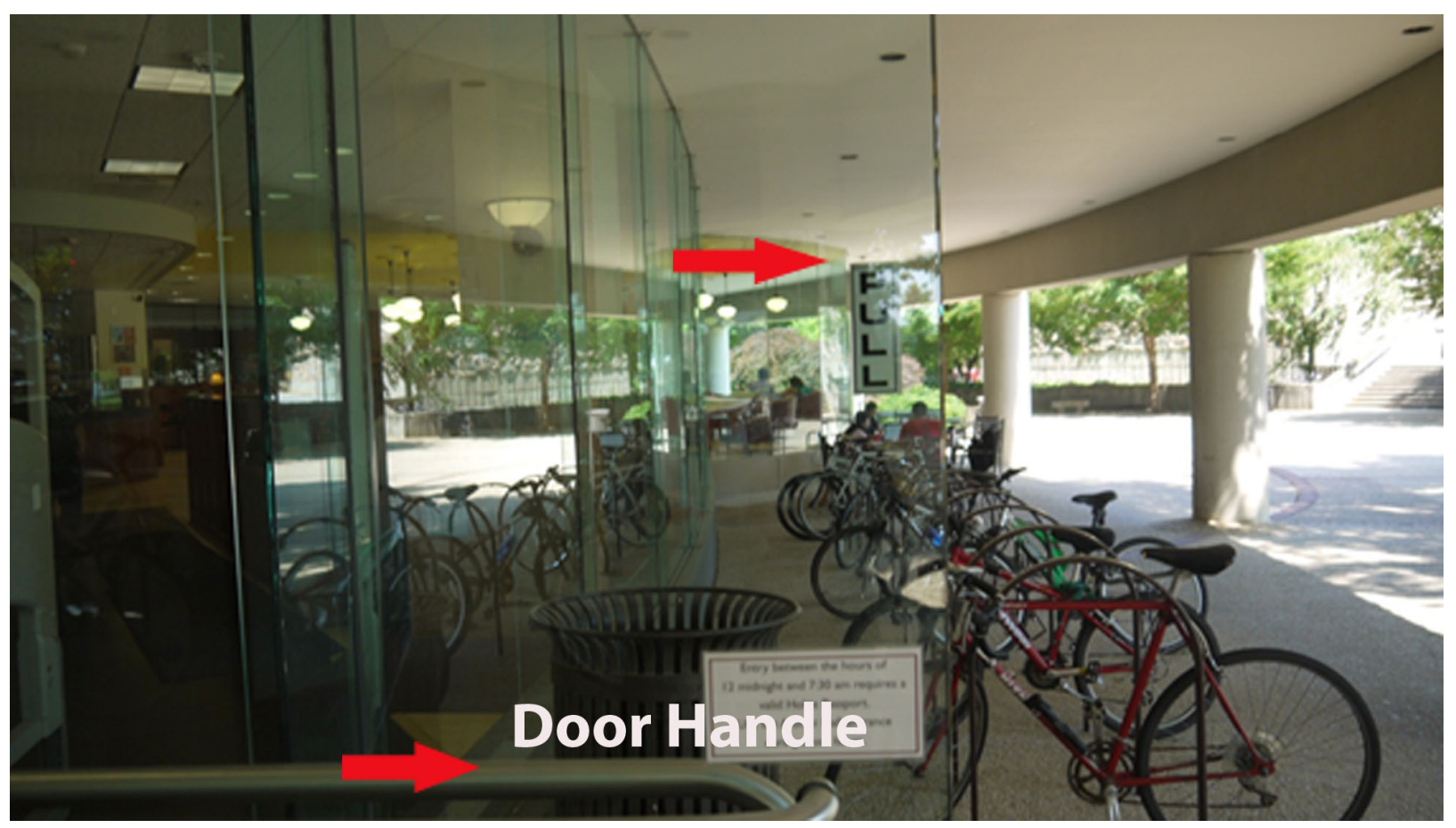

On minimalism, Johnson (2010) wrote, "Minimize the amount of prose text in a user interface; don't present users with long blocks of prose text to read" (Johnson, 2010, p. 50). In addition, Wroblewski (2011) noted that "When it comes to mobile forms, be brutally efficient and trim, trim, trim" (Wroblewski, 2011, p. 103). "One of the biggest challenges of designing interfaces for complex systems is figuring out which aspects the users don't need to deal with and reducing their visibility (or leaving them out altogether)" (Garrett, 2011, p.114).

Apart from the use of theory and principles in designing a user interface, designers use specific guidelines for the design of the information on the display screen. (Beynon-Davies, 1993, Chap.19; MacKenzie, 2003; Shneiderman, 1998, Chap. 9) These principles include choice of fonts, typeface, color, audio and consistency in the terminology (Obilade, 2016). If the same image would be displayed on a mobile phone and on a PC, determine the number of pixels that can be conveniently displayed on each device (Obilade, 2016). Referring to pixels 
on a mobile phone, Wrobleski (2011) wrote, "Pixel density impacts how physically big or small elements appear on a screen. A higher pixel density means each pixel is physically smaller" (Wroblewski, 2011. p.110).

\section{User-Friendly Guidelines From Theories of User-Interface Design}

1. State clear goals for the user-interface

2. Define the sub-goals

3. Define the motor and perceptual actions that must take place to achieve the goal.

4. Make the user-interface reflect the persona of the user

5. Know the physical characteristics of the user including his/her left/right handedness.

6. Know the motivation, attitudes, patience, expectations, stress level and cognitive style of the user.

7. Conduct a usability testing

8. Define the time it would take for the cursor to move from the time the pointing device is activated. This is important in gestural and gaze-based user interfaces.

9. If the same image would be displayed on a mobile phone and on a PC, determine the number of pixels that can be conveniently displayed on each device.

10. Avoid color combinations that color blind people would not be able to see. Red and green color combinations are not seen by people who are color blind.

11. Choose appropriate typeface, font and color.

12. Apply the principles of affordance.

13. Apply minimalism 


\section{LEARNER INTERFACE}

Moore (1989) classified the various interactions in distance learning into three categories. These interactions were learner-content, learner-instructor and learner-learner. Following these categorizations, Hillman, Willis and Gunawardena (1994) introduced the learner interface interaction as the interaction between the learners and the technology used to deliver the instruction. The learner interface became the fourth category in the various interactions in distance learning. It is the point of interaction "... between the learner and his or her content, instructor and fellow learners" (Hillman et al., 1994, p.32).

The learner interface is the medium through which the learner makes a point of contact with the content, the other learners and the instructor. It is through technology that the learner makes contact with the other interfaces. Lucas (1991) pointed out that the visual design of the learner interface affects the motivation of the learner.

The learner should be presented with visual hierarchies (Krug, 2014). Krug (2014) wrote, “... make sure that the appearance of the things on the page-all of the visual cuesaccurately portray the relationships between the things on the page: which things are similar, and which things are part of other things" (p.33). The visual design of the learner interface includes the graphical elements of an interface, the layout of the screen, and the images used to represent commands on the screen (Lucas, 1991).

Consistency in the text, consistency of the fonts and consistency in the icon would keep the learner focused on the learning material and keep him/her from wondering what inconsistent icons mean (Lucas, 1991 \& Galitz, 2002, Chap. 8). Headers should be placed consistently on the same spot on every page (Lucas, 1991). Designers should avoid the use of scrolling to the next page. Rather, they should have an icon that changes the pages (Galitz, 2002, Chap. 8). 
The design of the learner interface should make recovery from errors easy (Johnson, 2010; Krug, 2014; Wroblewski, 2011). "Minimizing the amount of navigation options on mobile screens helps to prevent errors as well” (Wroblewski, 2011, p. 65).

\section{Some Theories of Learner Interface Design}

The principles and guidelines from theories in learner interface must be applied to develop a user-friendly learner interface. Gnanam, Srinath and Sivhakumaar (2011) asserted that the learner interface consisted of cognitivist, constructivist and collaborative theory or a mixture of the three theories. Jones, Farquhar and Surry (1995) proposed the use of cognitive strategies in computer-based instruction.

These cognitive strategies are the methods through which information is stored, comprehended and retrieved from memory. They include methods like organization of learning material and use of schemas. Jones et al. (1995) proposed the use of metacognitive theories in the design of interfaces for computer-based instruction. The learner selects the most appropriate strategy for the particular learning problem. The learner controls the cognitive process through strategy selection. S/he monitors cognitive processes through goal setting and goal checking. The learner is able to change the cognitive strategy to another cognitive strategy if the one being used does not work.

The learner interface was successfully used as a constructivist educational tool in designing web-based video games that taught geography and physical sciences at the grade level (Vichido, Estrada \& Sanchez, 2003). They (Vichido et al., 2003) collected demographic data, data on experiences and interests of students before designing the learner interface for the students. In addition, the learners were given a pretest before exposing them to the concepts through video gaming. The results of the study showed that the students who learned the 
concepts of geography and the physical sciences through gaming scored higher than on the pretest.

Ortiz, Ayala and Osorio (2003) used a group-based zone of proximal development to develop a learner interface for computer supported collaborative learning (CSCL). They gathered information about learners and about what the designers believed about the learners. The information gathered from both learners and designers was used to develop the learner interface. They also had to get information on the various topics that those in the learning group were going to learn. Finally, Ortiz et al. (2003) used the knowledge from the group's zone of proximal development to develop the interface.

\section{User-Friendly Guidelines From Theories of Learner Interface Design}

1. Determine how the learner interface can motivate the learners.

2. Keep the visual design of the learner interface simple.

3. Be consistent in the use of texts, fonts and icons.

4. Place headers in the same spot on every page.

5. State unambiguous goals and set sub goals.

6. Determine what the designer believes about the learners.

7. Determine what the learners know about the lesson content before designing the module.

8. Use visual hierarchies.

9. Determine the learners' zones of proximal development.

\section{INSTRUCTIONAL DESIGN}

Instructional design is synonymous to instructional systems development (Molenda, 1997). Instructional system design is not instructional theory (Merrill, 1977). "Instructional 
design (ID) theory is a set of prescriptions for determining appropriate instructional strategies to enable learners to acquire instructional goals. ID theory is prescription based and is founded in learning theory and related disciplines" (Merrill, 1977, p. 381). It is a prescriptive theory because the theories predict the learning outcomes (Tennyson \& Schott, 1977).

The instructional design for the learning outcome is developed based on the instructional theory (Tennyson \& Schott, 1977). Instructional theory describes how the instructional design works and why it works while instructional design describes what to do through a series of systematically designed steps. It usually begins with a needs assessment. There are several models. Basically, instructional design can be divided into analysis, design, development, implementation and evaluation (ADDIE) (Merrill 1997; Molenda, 1997).

Instructional design has its origins in systems engineering and behaviorist psychology (Molenda, 1997). The early models of instructional design used engineering concepts and terminologies like feedback, input, output, channel and lead time (Molenda, 1977).

At the end of World War II, psychologists were invited by the Military to design and develop military training materials. They focused research on designing instruction specific to the learning outcome and developed a systems approach to analyze performances.

Skinner's work on programmed instruction was developed further by Gagné, Glaser and Pask (Tennyson \& Schott, 1977). These psychologists were employed by the military to design programmed instruction. After the development of Gagné's theory in the early sixties, instructional design moved towards a cognitive approach. Gagné's theory described how to achieve learning outcomes through segmented steps. In addition, Ausubel's theory of advance organizers and Vygostky's theory of zone of proximal development contributed to the shift from behaviorist to the cognitivist approach (Tennyson \& Schott, 1977). 
Andrews and Goodson (2011) reviewed 40 models of instructional design after identifying more than 60 models of instructional design. The results from their study were first published in 1980 (Andrews \& Goodson, 1980) but the results are still relevant today. They found that most of the models were either based on theoretical or on empirical origins. Some models were also based on the users' past experience.

\section{Some Theories of Instructional Design}

Instructional design is developed through use of learning theories and theories of instruction (Tennyson \& Elmore, 1977). These learning theories are embedded in cognitive roots. Schema theory, advance organizers, assimilation theory and discovery learning are all learning theories. The theories of instruction include elaboration theory, the Minnesota Adaptive Instructional System, knowledge representation and integrated instructional strategies.

\section{(i) Schema Theory}

The term schema was first used by Bartlett in 1932 (Tennyson \& Elmore, 1977). "For this combined standard, against which all subsequent changes of posture are measured before they enter consciousness, we propose the word schema" (Bartlett, 1932, p.199). Bartlett conducted his experiments by reading ghost stories from a North American folk-tale to participants and asking them to recall the stories (Bartlett, 1932).

The participants in his experiment did not come from the culture from which the ghost stories were taken from. He noticed that different participants relayed the stories by omitting parts that did not fit into their repertoire of ghost stories regardless of how many times the stories were retold. 
The participants also added parts that were not in the story to fit into their existing repertoire. He postulated that learners were able to recall material if they had a schema organized in their memory (Kintsch, 1997). Ausubel added that the interpretation of what the learner made of his /her schema was a cognitive process. Ausubel described the schemata as several slots inside the memory. These slots are filled with related information in an organized way by the learner for easy recall. However, when the learner does not store the information in an organized way, recall would be difficult or impossible (Obilade, 2016; Tennyson \& Elmore, 1977).

Agatha Christie's detective protagonist, Miss. Marple was describing schema when she said:

Has it ever occurred to you", the old lady went on, "how much we go by what is called, I believe, the context? There is a place in Dartmoor called Grey Wethers. If you were talking to a farmer there and mentioned Grey Wethers, he would probably conclude that you were speaking of these stone circles, yet it might be possible that you might be speaking of the atmosphere; and in the same way, if you were meaning the stone circles, an outsider, hearing a fragment of the conversation, might think you meant the weather. So when we repeat a conversation, we don't as a rule, repeat the actual words; we put in some other words that seem to us to mean exactly the same thing. (Christie, 1985, pp.

\section{(i) Advance Organizers}

Advance organizers are closely related to schema theory. Advance organizers help the learner to build a conceptual framework provided the 
material to be learnt has a structure (Ausubel, 1960; Tennyson \& Elmore, 1977). They cannot be used to learn new material like the Greek alphabet because the Greek alphabet cannot be broken into structure (Tennyson \& Elmore, 1977).

\section{(ii) Assimilation Theory}

Ausubel postulated that if the material to be learnt is connected to what the learner already knows, it makes meaningful learning for the learner. Assimilation theory works well for conceptual ideas but it does not work for learning technical details (Tennyson \& Elmore, 1977). The presentation of advance organizers of concepts and lessons that have structure at the beginning of the lesson would increase the assimilation of the new material because the new material can find a structure to anchor on.

\section{(iii) Discovery Learning}

Jerome Bruner's work and Gestalt psychology contributed to the development of discovery learning (Einsiedler, 1977). Discovery learning allows the learners to discover through inquiry under the guidance of a teacher and the learning material (Hammer, 1997).

Supporters of discovery learning are opposed to putting specific learning objectives in a lesson plan (Andrews \& Goodson, 2011). Discovery learning is not always welcome by teachers who want to teach by the rule (Hammer, 1997; Tennyson \& Elmore, 1997). Skeptics of discovery learning propose that discovery learning should be guided discovery and not just pure discovery (Mayer, 2004). Discovery learning is the practice of social constructivism or cognitive constructivism (Mayer, 2004). 


\section{User-Friendly Guidelines From Theories of Instructional Design}

1. Conduct a needs assessment

2. Use a design, development, implementation and evaluation method.

3. Determine the learning theories you would use in the lesson content.

4. Determine the model of instructional design that you would use (see Figure 7).

\section{Figure 7 Dick and Carey Model}

The Dick and Carey instructional design model is one of the several models of instructional design.

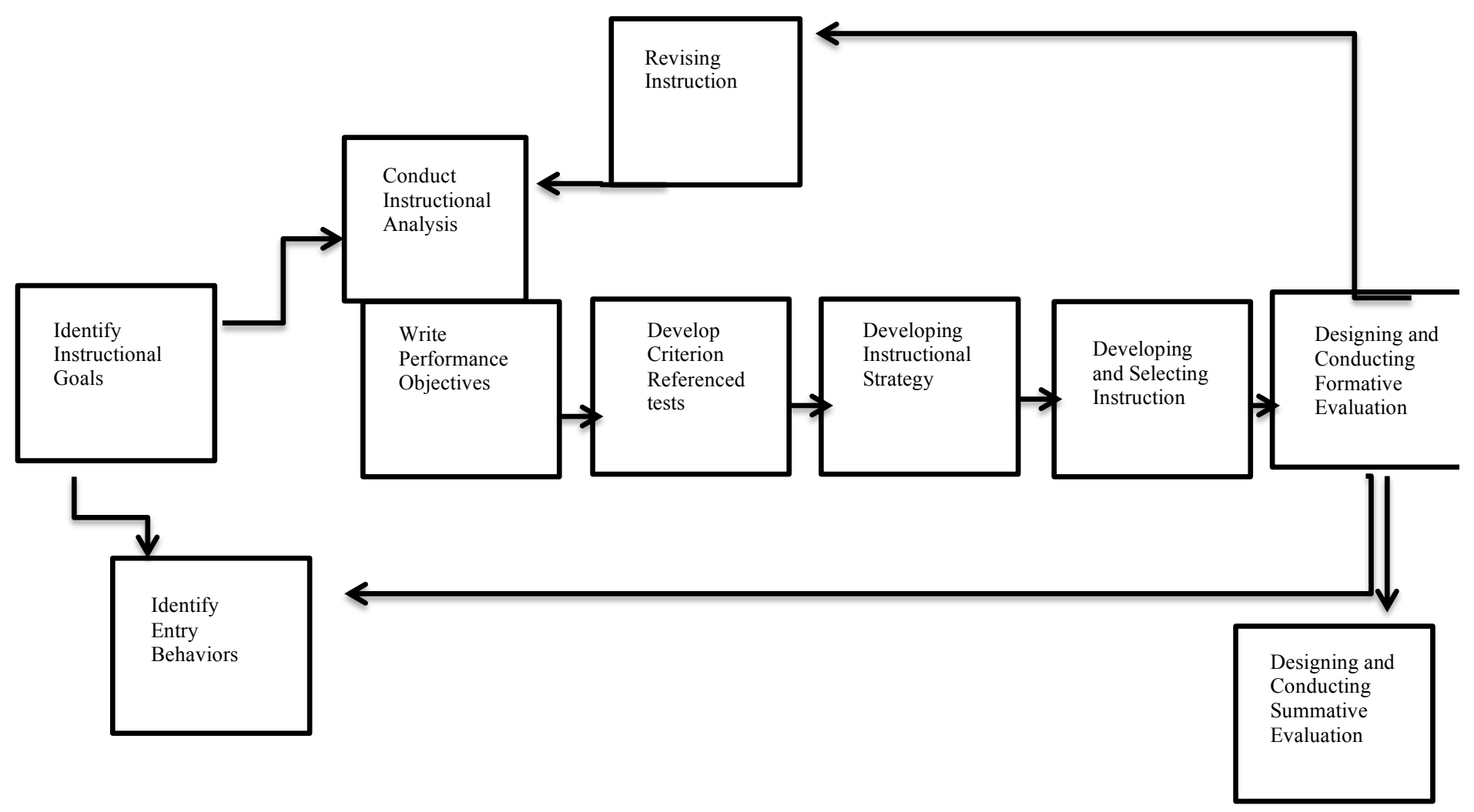


Figure 7. The Dick and Carey Model. Adapted from "A Model For The Systematic Design of Instruction,” by W. Dick, In R. Tennyson, F. Schott, N. Seel, \& S. Dijkstra (Eds.), Instructional Design: International Perspectives Volume 1: Theory, Research and Models, 1997, p. 365. Mahwah, New Jersey: Lawrence Erlbaum Associates.

\section{Similarities in User Interface Design, Learner Interface Design and Instructional Design}

In order to design a successful web site or develop a user-friendly online module, the three types of designs being examined in this chapter must consider the characteristics of the learner. The characteristics of the learner would be the age, sex, culture, entry-level competencies of the user, the right/left handedness of the user, the stress level, the patience, the motivating factors and other relevant information that can impact the learning process. The psychological attributes of the intended user must also be considered. There are similarities in the three designs (see Table 1).

Figure 8 illustrates the similarities in the designing of user and learner interfaces. The major steps of planning, designing, analyzing, testing and refining are the steps of instructional design in Figure 8. The steps in testing and refining would reflect the implementation and evaluation in the ADDIE model in instructional design. 
Figure 8. Alignments of User Interface, Learner Interface and Instructional Design

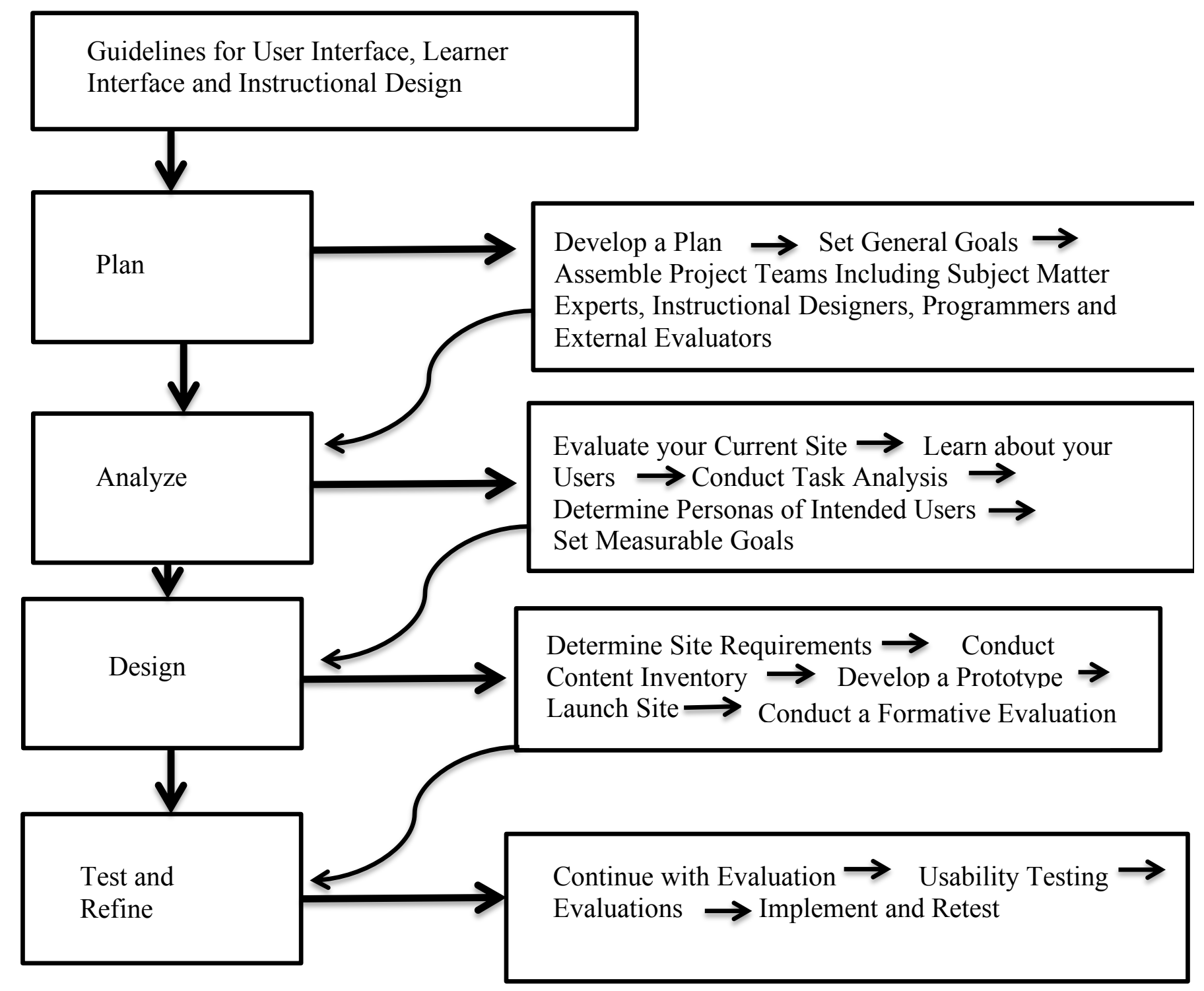


Table 1 Similarities

\author{
Learner Attributes \\ (Mandel, 1997, p. 256) \\ 2. Objectives \\ -Specifying the target audience \\ -Identifying the age bracket, user demographics, skills, \\ knowledge background,

\section{Perform User Analysis} \\ - State objectives of the design (Dick,1997, p.364) \\ (Dick, 1997, p. 365, Mandel, 1997, p. 256) \\ -Procedure-based task analysis and cognitive-based task analysis \\ -This analysis includes questions like; what steps are taken \\ to perform the task? \\ -What information is needed to complete the tasks? \\ 4. Gather User Requirements \\ -How frequently do users perform the task?
}

(Dick, 1997, p. 365, Mandel, 1997, p. 256)

-Gathering of user requirements and analysis would answer questions like:

-How much are users and managers willing to pay for the product?

-What should the interface feel like, what affordances would be used?

-Information for user requirements is gathered through focus

\title{
5. Analyze User Environment
} groups, structured interviews, and user surveys.

(Dick, 1997, p. 365, Mandel, 1997, p. 257)

-Where do the users perform their tasks?

-The designers would gather information on where the users would use the design.

-Will it be used on a mobile phone? Will it be used at home or in the office?

-What are the affordances in the physical environment? Light, noise and space. 
-The types of computers, Mac or PC.

-Human factors, ergonomics and physical considerations;

keyboard affordances, Users with special needs.

\section{Match Requirements to User Tasks}

(Dick, 1997, p. 365, Mandel, 1997, p. 257)

-Avoid excessive cognitive load

-If the feature is not necessary and is above what the users

7. Feedback need, the designer should not include it. Apply minimalism.

(Dick, 1997, p. 365, Mandel, 1997, p. 259)

-The designer should always go back to the user analysis phase and determine if the learner characteristics, the environment or other requirements have changed during the design and development process.

\section{Evaluation}

(Dick, 1997, p. 365, Mandel, 1997, p. 259)

\section{Theory}

\section{Collaboration}

11. History
-The designer should evaluate the design

-All the designs are based on one or more theories.

-There is collaboration of experts from different fields.

-The three designs were developed in response to post World War II.

Table 1 shows the similarities in the user interface, learner interface and instructional design. These similarities occur in the three designs already discussed in this chapter. The designer must know the attributes of the user or learner in all of the three designs. The designer must gather information about the tasks to be performed in all the three designs. The environment in which the design would be used must be analyzed in all the three designs. The three designs require collaboration from different experts. The three designs require feedback and evaluation of their processes. 


\section{Analogy of User Interface, Learner Interface and Instructional Design to a Car}

A lot of processes are involved before a car gets to the user. In this chapter, I have decided to use a car for simplicity. The driver is the user or learner. However, before purchasing the car, the user interface designer similar to the manufacturers would have determined the characteristics of the driver including policies that might affect the driver's experience. The instructional designer would have put the instructions on how to navigate the car in such a way that the driver would have an accident free driving experience. The learner interface would be the interactions the user (or driver) has with other road users.

\section{The Massive Open Online Courses (MOOC) Experience}

Massive Open Online Courses became popular after Stanford University began its MOOC in 2011. In the Stanford experience, one-sixth of the students completed the course (Rodriguez, 2012). Twenty thousand students had completed the course from over 190 countries (Rodriguez, 2012). Similar platforms to the MOOC are Coursera, EdX and Udacity.

The interest in MOOC is on the rise because it has been successfully used in many universities and is a welcome reduction in tuition costs. However, research has also shown that MOOC is facing many challenges. It has a low course completion rate, a high degree of student attrition, poor student engagement and poor student motivation (Gašević, Kovanović, Joksimović \& Siemens, 2014; Jordan, 2014; Jordan, 2015a; Jordan, 2015b; Koller, Ng, Do, \& Chen, 2013; Xiong et al., 2015). A review of research conducted on MOOC showed that lack of motivation of learners was responsible for a high attrition rate. Studies have shown that even though an average of 43,000 students enrolls in MOOC only $6.5 \%$ complete the courses (Jordan, 2014). 
Currently, there are several studies going on to explore the possible reasons for the low attrition rates. In sync with the ongoing studies, this chapter would recommend an exploration of the three designs examined in this chapter and alignment of the guidelines identified to developing a successful MOOC with less attrition.

\section{CONCLUSION}

The purpose of this chapter was to determine the implications of the similarities in user interface design, learner interface design and instructional design in developing a user-friendly online module. It examined the processes and similarities in the three designs that could be used in developing a user-friendly online module. The results of the review showed that the knowledge of learner attributes, the environment and performance user analysis contribute to the development of a user friendly-website in all the three designs studied.

User-friendly guidelines were garnered from the theories in each of the three designs; instructional design, learner interface design and user interface design. There were similarities in the learner attributes, objectives, task analysis, evaluation and in the collaboration of experts. Further, the chapter recommended an alignment of the garnered guidelines from the three designs to explore the plausible reasons for the high attrition rate in MOOC. 


\section{References}

Andrews, D. H., \& Goodson, L. A. (1980). A comparative analysis of models of instructional design. Journal of Instructional Development, 3(4), 2-16. doi: 10.1007/bf02904348

Andrews, D. H., \& Goodson, L. A. (2011). A comparative analysis of models of instructional design. In G. Anglin (Ed.). Instructional technology: Past, present, and future (pp. 205225). Santa Barbara, CA: Libraries Unlimited.

Ausubel, D. P. (1960). The use of advance organizers in the learning and retention of meaningful verbal material. Journal of Educational Psychology, 51(5), 267-272. doi:

$10.1037 / \mathrm{h} 0046669$

Bartlett, F. C., (1932). Remembering: A study in experimental and social psychology London: Cambridge University Press.

Beynon-Davies, P. (1993). Information systems development. Houndsmills, Basingstoke: The Macmillan Press Ltd.

Bowman, D. A., Kruijff, E., LaViola, J. J., \& Poupyrev, I. (2001). An introduction to 3-D user interface design. Presence: Teleoperators and Virtual Environments, 10(1), 96-108. doi: $10.1162 / 105474601750182342$

Christie, A. (1985). The thumbmark of St. Peter. In Miss. Marple: The complete short stories. (pp. 72-86). New York: G. P. Putnam's Sons.

Dick, W. (1997). A model for the systematic design of instruction. In R. Tennyson, F. Schott, N. Seel, \& S. Dijkstra (Eds.), Instructional design: International perspectives volume 1: Theory, research and models (pp.361-369). Mahwah, New Jersey: Lawrence Erlbaum Associates. 
Einsiedler, W. (1997). Research on instructional methods: An European perspective. In R. Tennyson, F. Schott, N. Seel, \& S. Dijkstra (Eds.), Instructional design: International perspectives volume 1: Theory, research and models (pp.1-16). Mahwah, New Jersey: Lawrence Erlbaum Associates.

Galitz, W. O. (2002). The essential guide to user interface design: An introduction to GUI design principles and techniques. New York: John Wiley \& Sons.

Garrett, J.J. (2011).The elements of user experience: user-centered design for the web and beyond. Berkeley, CA: New Riders.

Gašević, D., Kovanović, V., Joksimović, S., \& Siemens, G. (?2014). Where is Research on Massive Open Online Courses Headed? A Data Analysis of the MOOC Research Initiative. The International Review of Research in Open and Distant Learning.

Gnanam, S. P., Srinath, M. V., \& Sivhakumaar, V. P. (2011). Emerging web instructional design model for developing web based learning resources. European Journal of Scientific Research, 56(4), 548-555.

Hammer, D. (1997). Discovery learning and discovery teaching. Cognition and Instruction, 15(4), 485-529. doi: 10.1207/s1532690xci1504_2

Hennicker, R., \& Noch, N. (2001). Modeling the user interface of web applications with UML. In A. Evans, R. France, A. Moreira \& B. Rumpe (Eds.), Proceedings of the Practical UMLBased Rigorous Development Methods- Countering or Integrating the Extremists, Workshop of the Puml-Group Held Together with UML 2001, Toronto, Canada. Vol. P07. (pp. 158-172). Retrieved from http://subs.emis.de/LNI/Proceedings/ Proceedings07 /ModeltheUseInterf_12.pdf 
Hillman, D. C., Willis, D. J., \& Gunawardena, C.N. (1994) Learner-Interface interactions in distance education: An extension of contemporary models and strategies for practitioners. The American Journal of Distance Education 8(2) 30-42.

John, B. E. (2003). Information processing and skilled behavior. In J. Carroll (Ed.). HCI model, theories and frameworks: Towards a multidisciplinary science. (pp. 55-101). San Francisco, CA: Morgan Kaufmann.

John, B. E., \& Kieras, D. E. (1995). The GOMS family of user interface analysis techniques: Comparison and contrast. ACM Transactions Computer -Human Interaction, 3(4), 320351. doi: $10.1145 / 235833.236054$

Johnson, J. (2010). Designing with the mind in mind: simple guide to understanding user interface design rules. CA: Morgan Kaufmann.

Johnson, J., \& Henderson, A. (2002). Conceptual models: Begin by designing what to design. Interactions, 9(1), 25-32. doi: 10.1145/503355.503366

Jones, M. G., (1995). Visuals for information access: A new philosophy for screen and interface design. In D. Beauchamp, R. Braden, \& R. Griffen (Eds.), Imagery and visual literacy. (pp.264-272). International Visual Literacy Association.

Jones, M. G., \& Farquhar, J. D. (1997). User interface design for web-based instruction. In B. Khan (Ed.). Web-based instruction (pp. 239-254). Englewood Cliffs, NJ: Educational Technology.

Jones, M. G., Farquhar, J. D., \& Surry, D. W. (1995). Using metacognitive theories to design user interfaces for computer based learning. Educational Technology, 35(4) 12-22.

Jordan, K. (2014). Initial trends in enrolment and completion of massive open online courses. The International Review of Research in Open and Distance Learning, 15(1), 133-160. 
Jordan, K. (2015a). Massive Open Online Course Completion Rates Revisited: Assessment, Length And Attrition. The International Review of Research in Open and Distance Learning, 16(3), 341-358.

Jordan, K. (2015b). MOOC completion rates: The data. Retrieved from http://www.katyjordan.com/MOOCproject.html

Kintsch, W. (1997). Introduction. In F.C. Bartlett, Remembering: A study in experimental and social psychology (pp. xi-xvi). London: Cambridge University Press.

Koller, D., Ng, A., Do, C., \& Chen, Z. (2013). Retention and intention in massive open online courses: In depth. Educause Review, 48(3), 62-63.

Krug, S. (2014). Don't make me think, revisited: A common sense approach to web usability. California: Pearson Education.

Liang, C., Lee, Y-Z., \& Chou, W-S., (2010). The design considerations for game-based learning. Educational Technology, 50(2), 25-28.

Lü, H., \& Li, Y. (2011). Gesture avatar: A technique for operating mobile user interfaces using gestures. In D. Tan, S. Amershi, B. Begole, W. Kellogg \& M. Tungare (Eds.), Proceedings of the International Conference on Human Factors in Computing Systems, CHI May 7-12, 2011, Vancouver, BC, Canada: ACM.

Lucas, L. (1991). Visually designing the computer-learner interface. Educational Technology, 31(7), 56-58. 
MacKenzie, S. (2003). Motor behavior models for human-computer interaction. In J. Carroll (Ed.). HCI model, theories and frameworks: Towards a multidisciplinary science. (pp. 27-54). San Francisco, CA: Morgan Kaufmann.

Mandel, T. (1997). The elements of user interface design. New York: John Wiley \& Sons.

Marcus, A. (2002). Dare we define user-interface design? Interactions, 9(5), 19-24. doi:

$$
10.1145 / 566981.566992
$$

Mayer, R. E. (2004). Should there be a three-strikes rule against pure discovery learning? American Psychologist, 59(1), 14-19. doi: 10.1037/0003-066x.59.1.14

Merrill, M. D. (1997). Instructional transaction theory: An instructional design model based on knowledge objects. In R. Tennyson, F. Schott, N. Seel, \& S. Dijkstra (Eds.), Instructional design: International perspectives volume 1: Theory, research and models (pp. 381-394). Mahwah, New Jersey: Lawrence Erlbaum Associates.

Molenda, M. (1997). Historical and philosophical foundations of instructional design: A north American view. In R. Tennyson, F. Schott, N. Seel, \& S. Dijkstra (Eds.), Instructional design: International perspectives volume 1: Theory, research and models (pp. 41-53). Mahwah, New Jersey: Lawrence Erlbaum Associates.

Moore, M. G. (1989). Editorial: Three types of interaction. American Journal of Distance Education, 3(2), 1-7. doi: 10.1080/08923648909526659

Nielsen, J. (1993). Usability engineering. London: Academic Press.

Obilade, T.T. (2015). Affordances then and now: implications for designing instruction. Distance Learning, 12 (3): 9-16.

Obilade, T.T. (2016). Make Me See it: Pedagogical Strategies of Visual Literacy. Oklahoma: Tate Publishing. 
Ortiz, M. Ayala, G., \& Osorio, M. (2003). Formalizing the learner model for CSCL environments. In E. Chávez, J. Favela, M. Mejía, \& A. Oliart (Eds.), Fourth Mexican International Conference on Computer Science (pp. 151-158).

Rautaray, S., Kumar, A., \& Agrawal, A S. (2012). Perception and machine intelligence human computer interaction with hand gestures in virtual environment. Lecture Notes in Computer Science, 7143, 106-113. doi: 10.1007/978-3-642-27387-2_14

Ritchie, D. C., \& Hoffman, B. (1997). Incorporating instructional design principles with the world wide web. In Khan, B. (Ed.), Web-based instruction. (pp. 135-158). Englewood Cliffs, NJ: Educational Technology Publications.

Rodriguez, C. O. (2012). MOOCs and the AI-Stanford like Courses: Two successful and distinct course formats for massive open online courses. European Journal of Open, Distance, and E-Learning. Retrieved from http://www.eurodl.org/index.php?article=516

Shneiderman, B. (1998). Designing the interface: Strategies for effective human-computer interaction. Reading, MA: Addison-Wesley.

Shneiderman, B., \& Plaisant, C. (2010). Designing the interface: Strategies for effective humancomputer interaction. Reading, MA: Addison-Wesley.

Stellmach, S., \& Dachselt, R. (2012). Designing gaze-based user interfaces for steering in virtual environments. Paper Presented at the Proceedings of the Symposium on Eye Tracking Research and Applications, Santa Barbara, California. Retrieved from http://luxator.cs.uni-magdeburg.de/uise/Forschung/Publikationen/2012-ETRAGazeNavGUIs.pdf 
Tennyson, R. D., \& Elmore, R.L. (1997). Learning theory foundations for instructional design. In R. Tennyson, F. Schott, N. Seel, \& S. Dijkstra (Eds.), Instructional design: international perspectives volume 1: Theory, research and models ( pp. 55-78). Mahwah, New Jersey: Lawrence Erlbaum Associates.

Tennyson, R. D., \& Schott, F. (1997). Instructional design theory, research, and models. In R. Tennyson, F. Schott, N. Seel, \& S. Dijkstra (Eds.), Instructional design: International perspectives volume 1: Theory, research and models (pp. 1-16). Mahwah, New Jersey: Lawrence Erlbaum Associates.

Vichido, C., Estrad, M., \& Sanchez, A. (2003). A constructivist educational tool: Software architecture for web-based video games. In E. Chávez, J. Favela, M. Mejía, \& A. Oliart (Eds.), Fourth Mexican International Conference on Computer Science (pp. 144-150).

Vrasidas. C. (2011). Human-Computer interaction and usability of online learning environments. In G. Anglin (Ed.). Instructional technology: past, present, and future (pp. 227-235). Santa Barbara, CA: Libraries Unlimited.

Ware, C. (2003). Design as applied perception. In J. Carroll (Ed.). HCI model, theories and frameworks: Towards a multidisciplinary science. (pp.11-26). San Francisco, CA: Morgan Kaufmann.

Wroblewski, L. (2011). Mobile first. New York, NY: A Book Apart.

Xiong, Y., Li, H., Kornhaber, M.L., Suen, H.K., Pursel, B., \& Goins, D.D. (2015). Examining the relations among student motivation, engagement, and retention in a MOOC: A structural equation modeling approach. Global Education Review. 2(3), 23-33. 


\section{Biographical Statement}

Titilola Obilade is a medical doctor and a senior education specialist. She earned her Ph.D. in Learning Sciences and Technologies from Virginia Polytechnic Institute and State University. She is also an alumnus of University of Lagos, Nigeria where she earned her MBBS in Medicine and Surgery.

She has authored and coauthored more than 20 refereed articles, book chapters and a textbook in areas of instructional design and technology, human computer interaction, health education and infectious diseases. Her most recent work is a textbook on visual literacy. 